\title{
No initial size advantage for Japanese cedars in crowded stands
}

\author{
Biing T. Guan ${ }^{\mathrm{a}, *}$, Shu-Tzong Lin ${ }^{\mathrm{b}}$, Ya-Hui Lin ${ }^{\mathrm{a}}$, Yi-Sui Wu ${ }^{\mathrm{c}}$ \\ ${ }^{a}$ School of Forestry and Resource Conservation, National Taiwan University, Taipei 10617, Taiwan \\ ${ }^{\mathrm{b}}$ Department of Natural Resources, National Ilan University, Yi-Lan City 26042, Taiwan \\ ${ }^{\mathrm{c}}$ Experimental Forest, National Taiwan University, Chu-Shan 55743, Taiwan
}

Received 27 July 2007; received in revised form 8 October 2007; accepted 9 October 2007

\begin{abstract}
A long-standing and often contested issue in plant ecology is the "initial size advantage" hypothesis. Resolving the issue will clarify the roles of initial size in several areas of plant ecology. While the hypothesis has been examined several times, yielding supporting evidence for both sides of the argument, the hypothesis has rarely been tested with long-lived perennials under density stress. We tested the hypothesis based on the 2-m and 3-m spacing diameter growth data from a long-term Japanese cedar (Cryptomeria japonica) spacing trial, with relative diameter growth rate as a measure of overall competitive ability. We also determined the initial size effect duration. A two-parameter monomolecular model and nonlinear mixed-effects regression were employed to model individual tree diameter growth over a 50-year period in a retrospective and sequential manner, with initial diameter size class as the discrete fixed-effect covariate and stand age as the continuous covariate. The model's growth-rate parameter was used as a surrogate measure for relative diameter growth rate. All differences in size-class mortality rates were statistically not significant, except for two early inventories in the 3-m spacing. Survivors' mean diameter growth efficiency decreased with increasing initial size for the first 35 years for both spacings. Consequently, the differences in mean size-class DBH narrowed quickly for both spacings, and all size classes showed a similar mean DBH after 30 years. Initial size effects in terms of growth efficiency, lasted no more than 45 years for both spacings and with respect to mortality, lasted for no longer than 30 years for the 3-m spacing. Differential growth efficiency eliminated the initial size differences and prevented the development of a "hierarchy of exploitation" in diameter distributions. For Japanese cedars in the two spacings, a larger initial size did not confer a higher competitive ability or survivorship. It was growth efficiency that determined the ultimate fate of individual trees.
\end{abstract}

(C) 2007 Elsevier B.V. All rights reserved.

Keywords: Cryptomeria japonica; Initial size effect; Intraspecific competition; RGR; Spacing trial

\section{Introduction}

A long-standing and often contested issue in plant ecology is whether individual plants with a larger initial size are more competitive than their smaller cohorts (i.e., the "initial size advantage" hypothesis). Resolving this debate will elucidate the roles of initial size in competition, population size structure dynamics, and community composition dynamics (Harper, 1967, 1977). While many studies have demonstrated the initial size advantage seems to be valid (Harper, 1967, 1977; Ross and Harper, 1972; Ford, 1975), other studies have provided counter evidences (Newberry and Newman, 1978; Turner and Robinowitz, 1983; Wilson, 1988; Grace et al., 1992; Gerry and Wilson, 1995). Several studies (e.g., Newberry and Newman, 1978; Wilson, 1988; Stoll and Bergius, 2005) have

\footnotetext{
* Corresponding author. Tel.: +886 2 33664628; fax: +886 223639247 .

E-mail address: btguan@ntu.edu.tw (B.T. Guan).
}

suggested that initial size advantage applies to asymmetric competition (e.g., competition for light), but not to symmetric (e.g., belowground) competition. Newberry and Newman (1978) further suggested that if competitive ability decreases with increasing initial size, then there would be no initial size advantage. Although a plausible proposition, it has not yet been confirmed.

In this study, the initial size advantage is defined as "initially larger plants have higher relative growth rates (RGR) than smaller plants" (Ford, 1975; Wilson, 1988). As a measure of growth efficiency (Blackman, 1919), RGR is regarded as one of the best measures of competitive ability (Ford, 1975, 1984; Harper, 1977; Goldberg and Landa, 1991; Larocque and Marshall, 1993). This definition has two advantages. Firstly, the definition separates "mode of competition" from "utilization efficiency" (Schwinning, 1996; Berntson and Wayne, 2000). A larger plant may be able to acquire more resources due to sizeasymmetric competition (Weiner, 1990), but it may also have a low efficiency in converting acquired resources into subsequent 
growth due to its size (Schwinning, 1996; Berntson and Wayne, 2000). Secondly, with RGR as a measure of competitive ability, we can test the hypothesis directly as competitive ability is now measurable.

The first objective of this study was to test the initial size advantage hypothesis using 50-year inventory data from a Japanese cedar (Cryptomeria japonica D. Don) spacing trial. Although several studies have tested the hypothesis, it has rarely been tested with long-lived perennials under density stress. In addition, a related question generally missing from the debate is how long the initial size effects last. Such a question is important to understand the true nature of initial size effects (Grace et al., 1992). Thus, the second objective of this study was to determine the initial size effect duration in a dense population.

\section{Materials and methods}

\subsection{Description of the spacing trial and data}

The spacing trial is located in the National Taiwan University Experimental Forest Si-Tou Forest District of central Taiwan $\left(120^{\circ} 47^{\prime} \mathrm{E}, 23^{\circ} 40^{\prime} \mathrm{N}\right.$, elevation $\left.1200 \mathrm{~m}\right)$. The trial was established in 1950, using 1-year cuttings planted in square spacings of $1,2,3,4$, and $5 \mathrm{~m}$ (i.e., initial densities of $10,000,2500,1111,625$, and 400 trees/ha, respectively). The experimental design is a completely randomized design with three plots (replicates) for each spacing. The area of each plot is 0.1 ha $(25 \mathrm{~m} \times 40 \mathrm{~m})$, with a $5 \mathrm{~m}$ spacing between plots. The entire spacing trial was established within a 3-ha area. The first inventory was conducted in 1955, with subsequent inventories taken in 1960, 1965, 1980, 1985, 1995, 2000, and 2005. We will refer to the years since establishment as "stand age". While over-bark diameter at breast height (DBH, measured at $1.3 \mathrm{~m}$ above the ground) was measured for all survived trees in every inventory, only a portion of the trees was measured for their heights in the first two inventories. The 1-m spacing plots were thinned immediately after the 1965 inventory and were therefore excluded from the study. We included data from only the 2- and 3-m spacings because even at stand age 55, a complete canopy closure has not yet occurred for either the 4or 5-m spacings. In addition, to minimize edge effects, this study included only data from trees located approximately within the central $70 \%$ area of each of the six remaining plots (712 trees in total).

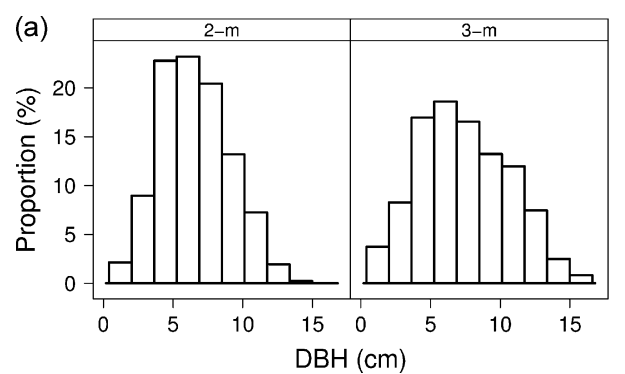

Based on DBH measurements recorded in 1955 (Fig. 1a), trees were classified as small, medium, or large within each spacing, and with each size class having approximately the same number of individuals (Fig. 1b). Although the size classes were established based on measurements taken 5 years after planting, we still regarded the measurements as initial sizes. We did not use tree height to establish initial size classes, as not every tree had a height measurement. However, based on trees with both measurements, height and DBH were significantly correlated at that age (Pearson's $r=0.90$ and 0.91 for the 2-m and 3-m spacings, respectively; both $P<0.001)$.

We used relative diameter growth rate $\left(\mathrm{RGR}_{\mathrm{DBH}}\right)$ as a measure of overall growth efficiency. Previous studies have suggested that diameter growth is last in the carbon allocation priority ranking for trees (Waring, 1983; Waring and Pitman, 1985). Therefore, any growth in $\mathrm{DBH}$ implies that a tree has acquired enough resources to meet all other demands. $\mathrm{RGR}_{\mathrm{DBH}}$ should therefore be an effective indication of a tree's overall growth efficiency (Larocque and Marshall, 1993; Larocque, 1998). However, Nilsson and Albrektson (1993) suggested that under intense competition for light, diameter growth becomes a high priority. Despite different views, both arguments suggest that $\mathrm{RGR}_{\mathrm{DBH}}$ should be a robust measure of a tree's competitive ability.

\subsection{DBH growth model}

The mean cumulative DBH growth over the 50-year period for all plots suggested a growth trend that followed a simple asymptotic curve (Fig. 2). Therefore, we adopted a twoparameter monomolecular model (Hunt, 1982) of the following form

$$
\operatorname{DBH}(t)=\operatorname{Asymp} \cdot[1-\exp (-\mathrm{rc} \cdot t)]
$$

to model DBH growth trends. In Eq. (1), DBH $(t)$ is $\mathrm{DBH}(\mathrm{cm})$ at stand age $t$ (years), Asymp is the asymptote $(\mathrm{cm})$ of the model, and rc is the growth-rate coefficient (year ${ }^{-1}$ ).

From Eq. (1), we can derive

$$
\operatorname{RGR}_{\text {DBH }}(t)\left(\mathrm{cm} \mathrm{cm}^{-1} \text { year }^{-1}\right)=\frac{\mathrm{rcexp}(-\mathrm{rc} \cdot t)}{1-\exp (-\mathrm{rc} \cdot t)}
$$

as the instantaneous relative $\mathrm{DBH}$ growth rate at stand age $t$ (Hunt, 1982). It is clear from Eq. (2) that $\mathrm{RGR}_{\mathrm{DBH}}$ is independent of tree size and a monotonically decreasing function of rc (Fig. 3). Because of the monotonicity, we used rc as a surrogate measure for $\mathrm{RGR}_{\mathrm{DBH}}$.

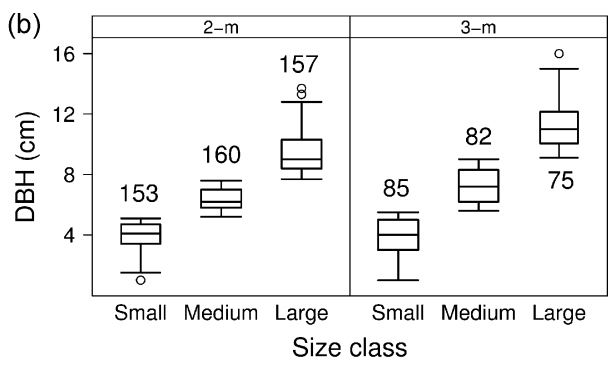

Fig. 1. Based on the 1955's DBH measurements (a) size distributions for the two spacings, and (b) box plots for size classes in the two spacings together with the initial number of trees in each size class. 


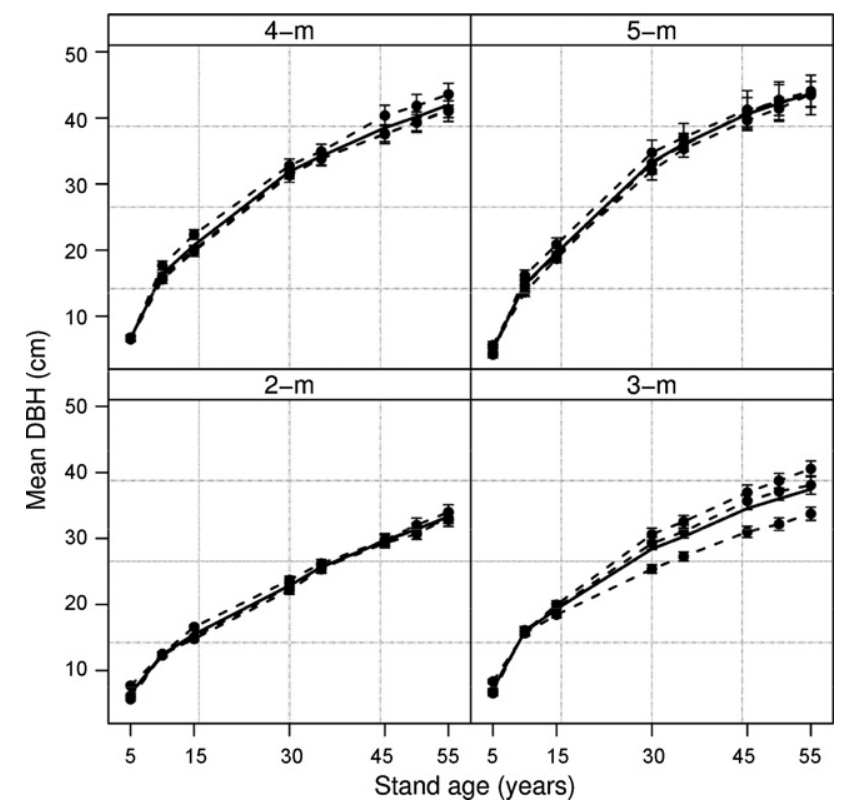

Fig. 2. Mean DBH growth trends for four spacings in the Japanese cedar spacing trial. The dashed lines represent the plot-level mean trends, the solid lines represent the mean spacing trends, and the error bars represent the plotlevel means \pm 1S.E.

\subsection{Statistical analyses}

Because the data were longitudinal and may be heteroscedastic, we used either a generalized nonlinear least-squares or a nonlinear mixed-effects (NLME) regression approach to account for serial correlations and heteroscedasticity. We modeled tree growth by NLME, if it was necessary to treat any of the two parameters in the above monomolecular model as a mixed-effect. In mixed-effects modeling, a fixed effect represents the population average, whereas the associated

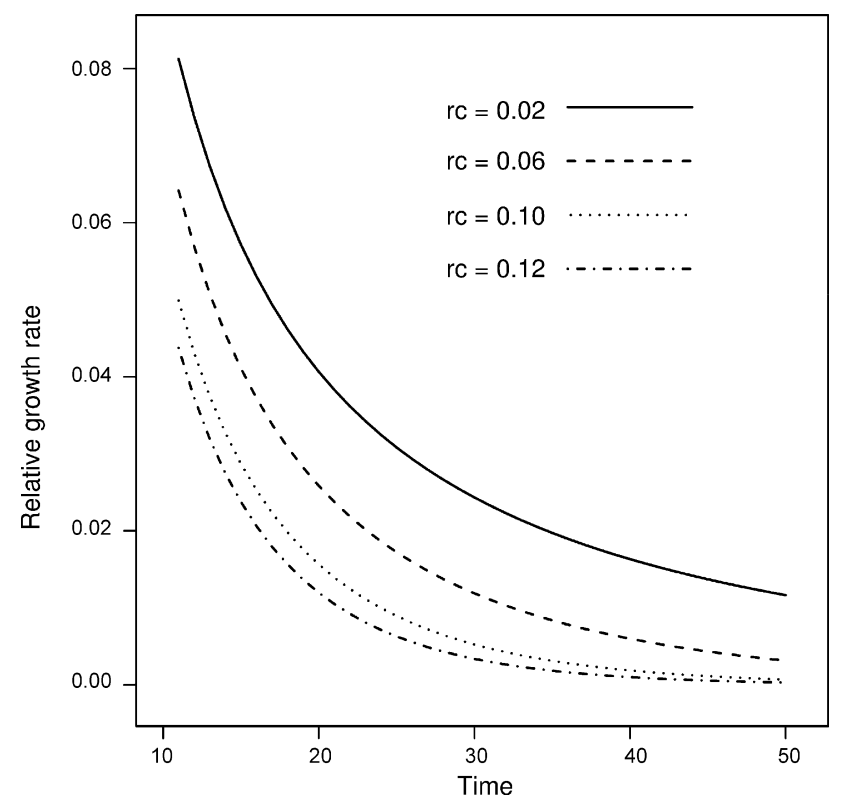

Fig. 3. Relative growth rate as a function of growth-rate parameter (rc) and time. random effect represents random deviations of individual trees from the fixed effect (Pinheiro and Bates, 2000). In all cases, a two-level modeling approach was adopted, with plots as the first level and individual trees within each plot as the second level (i.e., trees nested within a plot). Environmental heterogeneities may be responsible for random variation at the plot level, whereas random variation at the tree level might be due to within-plot heterogeneities (e.g., Burdon and Harper, 1980) or genetic differences. In all models, stand age was the continuous covariate, and initial size class was the discrete fixed-effect covariate.

Our analysis required at least three data points in time to fit the nonlinear growth model, therefore we began the growth analysis with the 1965 (third) inventory. For each survivor in the $i$ th $(i=3,4, \ldots, 8)$ inventory, we modeled its cumulative diameter growth between the first and the $i$ th inventory. The approach was therefore retrospective and sequential. We analyzed each spacing separately. We fitted 12 models, six for each spacing.

All statistical analyses were conducted using $\mathrm{R}$ ( $\mathrm{R}$ Development Core Team, 2007). We used the NLME package of R (Pinheiro et al., 2007) to fit generalized nonlinear leastsquares and NLME models. We used graphical methods (e.g., residuals diagnostic plots, the observed trend augmented by the fitted trend plots, etc.) and the squared Pearson's correlation coefficient $\left(r^{2}\right)$ between the observed and the fitted values to assess the adequacy and performance of a final fitted model.

\section{Results}

\subsection{Summary of modeling results}

In the majority of the data sets, at least one of the parameters was considered a mixed-effect. This result indicated that a considerable amount of random variation was present for both parameters at either the plot level, the tree level, or both levels. All the random effects met the normality assumption. The standardized residuals met the normality assumption for all data sets with three exceptions. In these three cases, the distribution of the standardized residuals was symmetric, but heavy tailed. We chose not to delete the outliers or to transform the data, since such a residual pattern tends to inflate the estimated within-group error variance and leads to more conservative tests (Pinheiro and Bates, 2000).

In most cases, the within-group heteroscedasticity was overcome by a combination of an exponential or a power variance function (varExp or varPower option, respectively, in NLME) with stand age as the variance covariate, and a scaling of the within-group variance estimate for each size class or each plot (varIdent option in NLME). We accounted for the serial correlation by using either an $\operatorname{AR}(1), \operatorname{ARMA}(1,1)$, or $\mathrm{MA}(2)$ process (Pinheiro and Bates, 2000; Pinheiro et al., 2007).

The predicted mean DBH growth trends of the 12 fitted models matched the corresponding observed trends closely, with the exception of the two models based on the 1965 data (Figs. 4 and 5). The less than satisfactory performance of those 

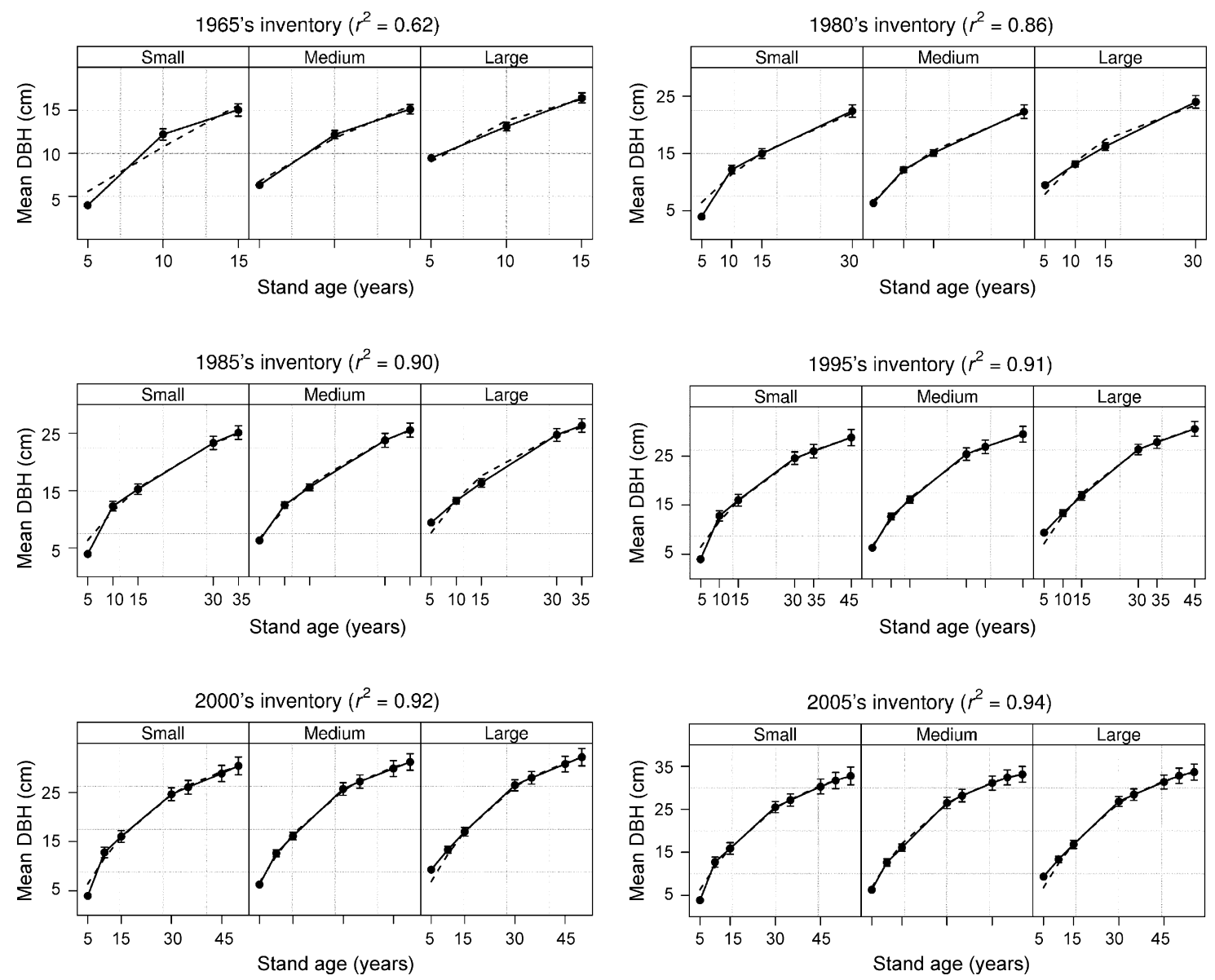

Fig. 4. Observed and fitted mean size-class DBH trends for the six inventory data sets in the 2-m spacing. In each panel, solid lines are the observed trends, dashed lines are the fitted trends, and error bars represent the observed means \pm 2S.E. The squared Pearson's correlation coefficient $\left(r^{2}\right)$ between individual observed and fitted values is also given for each fitted model.

models was mainly the result of fitting a nonlinear model with only three data points.

\subsection{Mortality and tree growth}

The overall mortality rates for the 2- and 3-m spacings were $63 \%$ and $36 \%$, respectively. Following previous studies (Westoby, 1984; Weiner and Thomas, 1986; Knox et al., 1989), we arbitrarily set the onset of significant self-thinning as when the cumulative mortality of a spacing reached $20 \%$. Based on this criterion, significant self-thinning began between stand ages 15 and 30 for the $2-\mathrm{m}$ spacing. Significant mortality did not occur until after stand age 35 for the 3-m spacing (Fig. 6). However, self-thinning was likely not the only cause of mortality. Density-independent factors (e.g., typhoons) probably also contributed to mortality. In general, larger trees are more susceptible to wind damage than their smaller neighbors are (Gardiner et al., 1997).

All size classes in the 2-m spacing had similar mortality rates over the study period (Fig. 6b). For the 3-m spacing, the smallest size class had the highest mortality throughout the inventories. All differences in size-class mortality rates were statistically not significant (all $P>0.05, \chi^{2}$-test) for both spacings, with the exception of the second and the third inventories of the 3-m spacing, where mortality only occurred in the smallest size class.

The mean DBH of the 3-m spacing was larger than that of the 2-m spacing over the study period (Figs. 2 and 7). In 1955, the mean size-class DBHs within each spacing were significantly different from each other (all $P<0.001$, Tukey's test; Fig. 7). However, the differences narrowed quickly after the first inventory. For both spacings, the mean DBHs of the two smaller size classes remained smaller than that of the largest size class (all $P<0.05$; Fig. 7) during the first $10-15$ years. All size classes shared a similar mean DBH after 30 years.

\subsection{Growth efficiency of survivors}

During the first 35 years, the mean size-class rc values for survivors in the 2-m spacing were all significantly different from each other (all $P<0.01$, Fig. 8), with the smallest size class having the lowest mean rc value (i.e., the highest mean $\left.\mathrm{RGR}_{\mathrm{DBH}}\right)$. In the remaining three inventories, the values were similar. The mean re trend for survivors in the 3-m spacing was similar to that for survivors in the 2-m spacing with one exception. For the 3-m spacing at stand age 35, only the mean rc values between the smallest and the largest size classes differed 

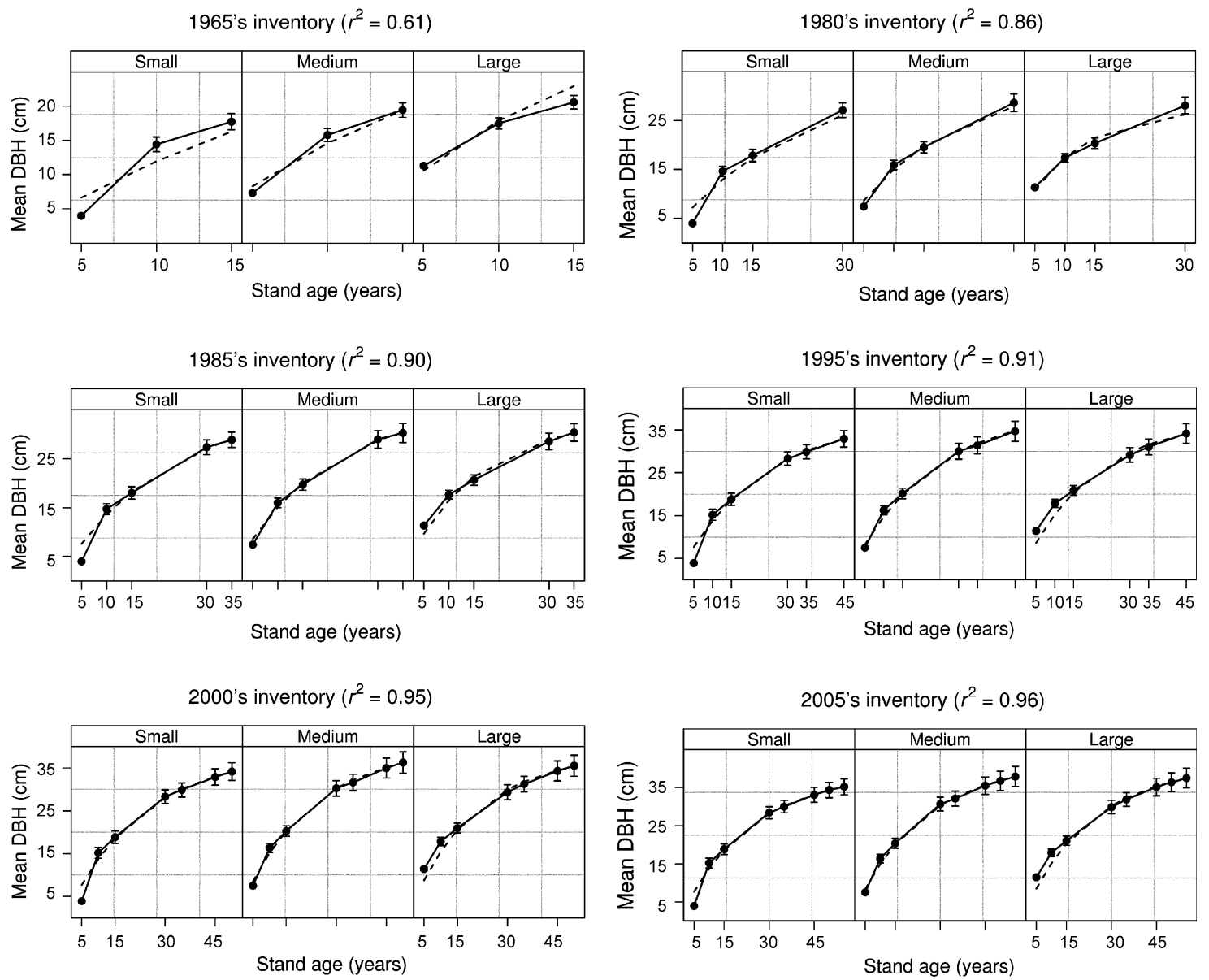

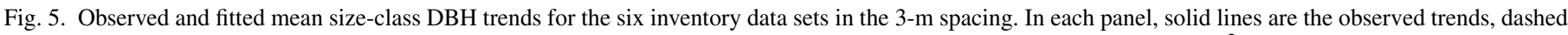

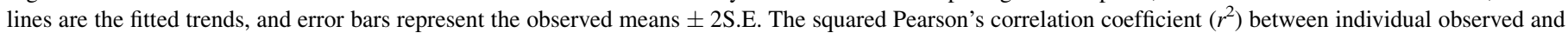
fitted values is also given for each fitted model.

significantly $(P=0.026)$. At stand age 45 , the survivors' mean size-class rc values converged in both spacings. Furthermore, at stand age 55 , survivors in the 2 -m spacing had a lower overall mean rc value than that of the $3-\mathrm{m}$ spacing survivors $(0.038$ and 0.047 year $^{-1}$, respectively).

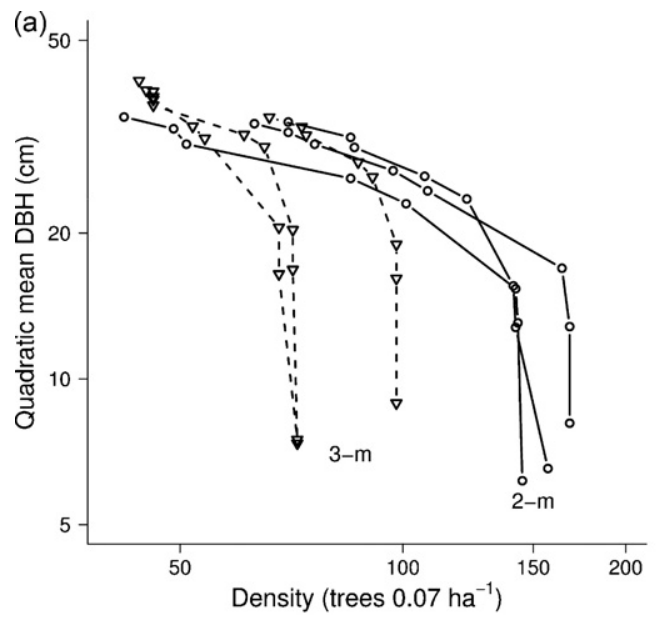

\section{Discussion}

Starting from the third inventory, the mean DBH for the 2- or 3-m spacing was less than that for either the 4- or 5-m spacings (Fig. 2). The overall mortality rates for the 2- and 3-m spacings

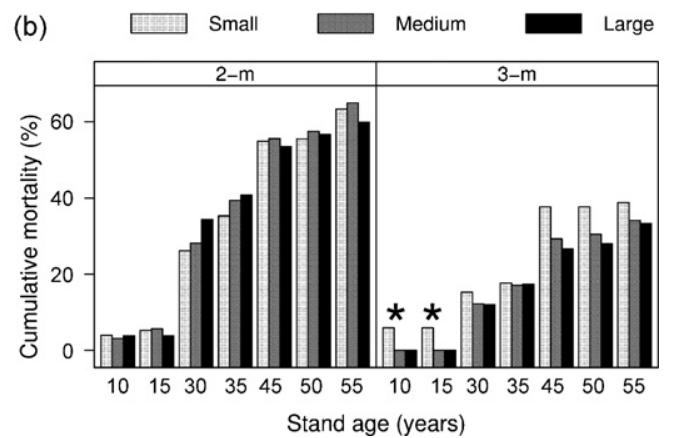

Fig. 6. (a) Plot-level residual density and quadratic mean DBH relationship ( $\log -\log$ scale), and (b) cumulative size-class mortality rates for each inventory with (*) denoting that the size-class mortality rates were significantly different at $\alpha=0.01$ level based on a $\chi^{2}$-test. 


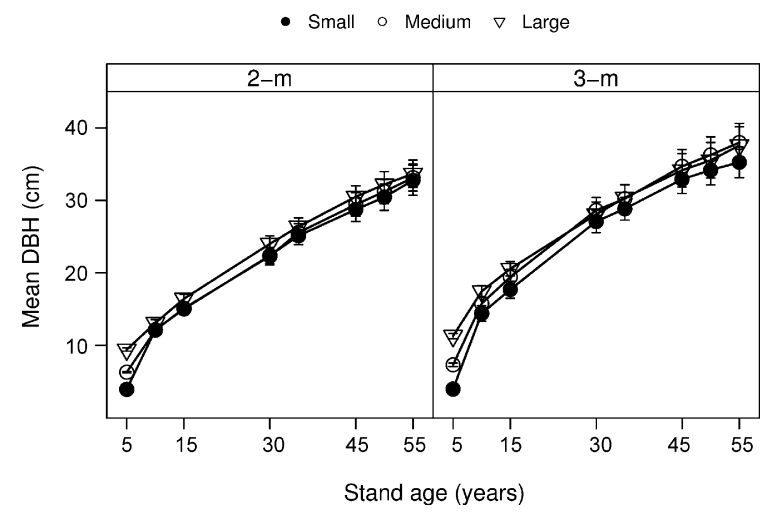

Fig. 7. Mean size-class DBH trends for the two spacings. The error bars represent the means \pm 2 S.E.

were also higher than those for the 4- and 5-m spacings, which were $24 \%$ and $26 \%$, respectively. Both results indicated that intense competition did occur in the 2-m and 3-m spacings (Turner and Robinowitz, 1983).

In both spacings, survivors' mean diameter growth efficiency decreased with increasing initial size during the first 30-35 years (Fig. 8). Our results provided evidence contrary to what many previous studies have suggested (Harper, 1967, 1977; White and Harper, 1970; Ross and Harper, 1972; Ford, 1975) and supported the proposition by Newberry and Newman (1978) that competitive ability can decrease with increasing initial size. Thus, with respect to growth efficiency, no initial size advantage for Japanese cedars in the two spacings was evident.

If the initial size advantage holds, as a stand matures the development of a clear size hierarchy is inevitable (the snowballing effect, Newman, 1973). In some extreme cases, the size distributions could even become bimodal (e.g., Ford, 1975). However, a "hierarchy of exploitation" (Harper, 1977) in diameter distributions never developed over the entire study period in both spacings (Fig. 7). The differential growth efficiency was responsible for reducing the initial size differences and consequently stabilizing the diameter distributions (Turner and Robinowitz, 1983).

The diameter growth efficiency trends were likely competition-induced. Five years after the establishment of the spacing trial, some degree of size differential had already occurred

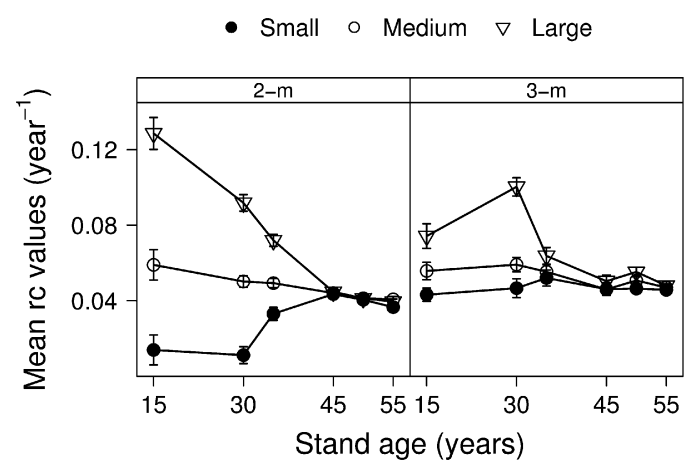

Fig. 8. Estimated survivors' mean size-class rc values at different stand ages for the two spacings. The error bars represent the means \pm 1 S.E.
(Fig. 1a). As the competition intensity was likely low during those initial years (Fig. 6), trees were probably acquiring resources proportional to their size (Schwinning, 1996; Schwinning and Weiner, 1998), and growth efficiency was not critical to survival. Larger trees were getting larger because they had higher absolute growth rates. Once competition began to intensify, however, smaller trees must avoid being overtopped to survive. To grow tall, they also have to make a substantial radial growth for mechanical support (Nilsson and Albrektson, 1993) and achieve it efficiently (Schwinning and Weiner, 1998) since they probably have less resources available to them under size-asymmetric competition (Weiner, 1990). On the other hand, larger individuals presumably still had more resources available, but also possessed greater amounts of nonproductive tissues to maintain (Schwinning and Weiner, 1998; Perry, 1985). Thus, larger trees might not have as high a level of efficiency in diameter growth as their smaller neighbors (Schwinning, 1996; Perry, 1985). However, once survivors reached a certain size, they all had comparable amounts of available resources and overhead costs, and thus their growth efficiency converged, regardless of initial size. The lessening of density stress through time due to mortality also contributed to the convergence in growth efficiency (Figs. $6 \mathrm{~b}$ and 8), as growth efficiency might not be critical to survival once again.

Previous studies have suggested that the main victims of self-thinning are smaller trees (e.g., White and Harper, 1970; Ford, 1975; Harper, 1977; Westoby, 1984). Our results suggested that size might not be the sole determinant, as all size classes in both spacings had similar mortality rates in each inventory, with two exceptions (Fig. 6b). Consequently, a larger initial size did not guarantee a substantially higher survivorship. One possible explanation is that self-thinning mainly eliminated the growth inefficient trees. This assertion is supported by the decreasing trends in survivor's mean rc values and the associated standard errors for the two larger size classes (Fig. 8). The increase in survivor's mean rc value at stand age 30 , for the largest size class, in the 3-m spacing might be due to density-independent mortality. Therefore, we further suggest that the victims of self-thinning are likely growth inefficient.

Our results showed that initial size effects did exist, as different size classes had different growth performances. However, with respect to competitive ability, our results were incongruent with what the initial size advantage hypothesis predicted. Furthermore, initial size effects were not maintained (Grace et al., 1992). In terms of growth efficiency, the initial size effects lasted no more than 45 years for both spacings. After that time, all survivors had the same diameter growth efficiency (Fig. 8). With respect to mortality, in the 2-m spacing all size-class mortality rates were similar following the second inventory (Fig. 6b). The initial size effect lasted no more than 30 years in the 3-m spacing, after which time all size-class mortality rates were comparable.

Many existing plant competition models implicitly assume that initial size advantage exists and is maintained indefinitely. Our results demonstrated that the assumption may not hold. Of course, for plants all competitions are local. What matters is not the absolute size of a plant, but its size relative to its immediate 
neighbors (e.g., Harper, 1977; Stoll and Bergius, 2005). Since no relative size information is available for each tree, we can only rely on a mean performance approach. Nevertheless, we have provided compelling evidences that for Japanese cedars in crowded stands, a larger initial size did not guarantee a higher competitive ability or survivorship. It was growth efficiency that determines the ultimate fate of individual trees.

\section{Acknowledgements}

Funding for this study was partially supported by National Science Council of Taiwan (NSC 94-2621-B-002-014). We deeply appreciate National Taiwan University Experimental Forest for permission to the use the data and for providing field supports. We also thank three reviewers for their valuable comments.

\section{References}

Blackman, V.H., 1919. The compound interest law and plant growth. Ann. Bot. 33, 353-360.

Berntson, G.M., Wayne, P.M., 2000. Characterizing the size dependence of resource acquisition within crowded plant populations. Ecology 81, 10721085.

Burdon, J.J., Harper, J.L., 1980. Relative growth rate of individual members of a plant population. J. Ecol. 68, 953-957.

Ford, E.D., 1975. Competition and stand structure in some even-aged plant monocultures. J. Ecol. 63, 311-333.

Ford, E.D., 1984. The Dynamics of Plantation Growth. In: Bowen, G.D., Nambiar, E.K.S. (Eds.), Nutrition of Plantation Forests. Academic Press, London, pp. 17-52.

Gardiner, B.A., Stacey, G.R., Belcher, R.E., 1997. Field and wind tunnel assessments of the implications of respacing and thinning for tree stability. Forestry 70, 233-252.

Gerry, A.K., Wilson, S.D., 1995. The influence of initial size on the competitive responses of six plant species. Ecology 76, 272-279.

Goldberg, D.E., Landa, K., 1991. Competitive effect and response: hierarchies and correlated traits in the early stages of competition. J. Ecol. 79, 10131030 .

Grace, J.B., Keough, K., Guntenspergen, G.R., 1992. Size bias in traditional analyses of substitutive competition experiments. Oecologia 90, 429-434.

Harper, J.L., 1967. A Darwinian approach to plant ecology. J. Ecol. 55, 247270.

Harper, J.L., 1977. Population Biology of Plants. Academic Press, New York.

Hunt, R., 1982. Plant Growth Curves: The Functional Approach to Plant Growth Analysis. Edward Arnold, London.
Knox, R.G., Peet, R.K., Christensen, N.L., 1989. Population dynamics in loblolly pine stands: changes in skewness and size inequality. Ecology 70, 1153-1167.

Larocque, G.R., Marshall, P.L., 1993. Evaluating the impact of competition using relative growth rate in red pine (Pinus resinosa Ait.) stands. For. Ecol. Manage. 58, 65-83.

Larocque, G.R., 1998. Functional growth analysis of red pine trees under variable intensities of competition. For. Chron. 74, 728-735.

Newberry, D.McC., Newman, E.I., 1978. Competition between grassland plants of different initial sizes. Oecologia 33, 361-380.

Newman, E.I., 1973. Competition and diversity in herbaceous vegetation. Nature 244, 310-311.

Nilsson, U., Albrektson, A., 1993. Productivity of needles and allocation of growth in young Scots pine trees of different competitive status. For. Ecol. Manage. 62, 173-187.

Perry, D.A., 1985. The competition process in forest stands. In: Cannell, M.G.R., Jackson, J.E. (Eds.), Attributes of Trees as Crop Plants. Institute of Terrestrial Ecology, Huntingdon, pp. 481-506.

Pinheiro, J.C., Bates, D.M., 2000. Mixed-effects Models in S and S-Plus. Springer, New York.

Pinheiro, J.C., Bates, D.M., DebRoy, S., Sarkar, D., 2007. NLME: linear and nonlinear mixed effects models. R package version 3.1-83.

R Development Core Team, 2007. R: a language and environment for statistical computing. R Foundation for Statistical Computing, Vienna. R version 2.5.1.

Ross, M.A., Harper, J.L., 1972. Occupation of biological space during seedling establishment. J. Ecol. 60, 77-88.

Schwinning, S., 1996. Decomposition analysis of competitive symmetry and size structure dynamics. Ann. Bot. 77, 47-57.

Schwinning, S., Weiner, J., 1998. Mechanisms determining the degree of size asymmetry in competition among plants. Oecologia 113, 447-455.

Stoll, P., Bergius, E., 2005. Pattern and process: competition causes regular spacing of individuals within plant populations. J. Ecol. 93, 395-403.

Turner, M.D., Robinowitz, D., 1983. Factors affecting frequency distributions of plant mass: the absence of dominance and suppression in competing monocultures of Festuca paradoxa. Ecology 64, 469-475.

Waring, R.H., 1983. Estimating forest growth and efficiency in relation to canopy leaf area. Adv. Ecol. Res. 13, 327-354.

Waring, R.H., Pitman, G.B., 1985. Modifying lodgepole pine stands to change susceptibility to mountain pine beetle attack. Ecology 66, 889-897.

Weiner, J., 1990. Asymmetric competition in plant populations. Trends Ecol. Evol. 5, 360-364.

Weiner, J., Thomas, S.C., 1986. Size variability and competition in plant monocultures. Oikos 47, 211-222.

Westoby, M., 1984. The self-thinning rule. Adv. Ecol. Res. 14, 167-225.

White, J., Harper, J.L., 1970. Correlated changes in plant size and number in plant populations. J. Ecol. 58, 467-485.

Wilson, J.B., 1988. The effect of initial advantage on the course of plant competition. Oikos 51, 19-24. 